\title{
Analysis on the effect of different fracture geometries on the productivity of tight gas reservoirs
}

\author{
Temoor Muther a, ${ }^{,}$, Adnan Aftab Nizamani ${ }^{a}$, Abdul Razak Ismail b \\ a Department of Petroleum and Natural Gas Engineering, Mehran UET SZAB Campus, Khairpur Mirs', Sindh, Pakistan \\ ${ }^{b}$ Department of Petroleum Engineering, Faculty of Engineering, Universiti Teknologi Malaysia, 81310 UTM Johor Bahru, Johor, Malaysia \\ * Corresponding author: temoormuther@ymail.com, temoormuther@muetkhp.edu.pk
}

\section{Article history}

Received 27 November 2018

Revised 18 August 2019

Accepted 18 September 2019

Published Online 15 April 2020

\section{Graphical Abstract}

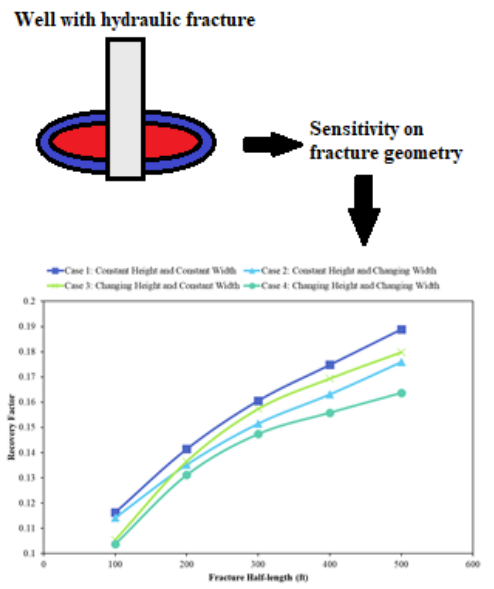

\begin{abstract}
Tight gas reservoirs are unconventional reservoir assets which have been the focus of major research in the petroleum industry owing to the global decline in conventional reservoirs. They are widely unlocked by creating hydraulic fractures in the formation to increase the flow capacity and productivity. The objective of this paper is to analyze different fracture geometries and their effect on tight gas production. The reservoir simulation model of the tight gas reservoir has been built with single porosity approach. A single vertical well with a single stage fracture has been used in the model to predict the behavior of fracture geometry. The major parameters of fracture geometry studied are fracture half-length, fracture width, and fracture height. Four sensitivities are run over different fracture geometry that is constant height and constant width, constant height and changing width, changing height and constant width, and changing height and changing width, while increasing the fracture half-length from $100 \mathrm{ft}$ to $500 \mathrm{ft}$ in each case. Sensitivity analysis exhibited that keeping the hydraulic fracture at constant height and constant width while increasing the fracture half-length resulted in enhanced tight gas productivity i.e. $11.63 \%, 14.14 \%, 16.06 \%, 17.48 \%$, and $18.89 \%$ at hydraulic fracture half-lengths of $100 \mathrm{ft}, 200 \mathrm{ft}, 300 \mathrm{ft}, 400 \mathrm{ft}$, and $500 \mathrm{ft}$, respectively, compared to other types of fracture geometry.
\end{abstract}

Keywords: Fracture geometry, unconventional reservoirs, tight gas productivity, hydraulic fracturing

\section{INTRODUCTION}

Fossil fuels have remained to be the major source of the world's energy demand while conventional reservoirs are at declining phase. Since two decades ago, researchers are more focused in exploiting unconventional reservoirs than conventional reservoirs [1]. Tight gas reservoirs are one of most common types of unconventional reservoirs. Tight gas sandstone reservoir is described as the one with permeability less than $0.1 \mathrm{md}$ irrespective of their depositional mechanisms [2]. Tight gas reservoirs have been characterized with low porosity, low permeability, high heterogeneity, extensive hydrocarbon generation, and complex pressure system [3]. The tight gas is very difficult to be produced economically because of its low permeability therefore it requires hydraulic fracture treatment to increase the gas recovery [4-7].

Hydraulic fracture treatment involves the injection of fluid in the formation which creates permeable channels (fractures) into the formation. The proppants are then injected with the fracturing fluids to keep the created fracture open. This causes an increased productivity of the reservoir fluids. The proppants thus are very important for the size of a fracture and it is obvious that more propped volume results in better recovery of the reservoir fluids if the placement of proppants is in the right direction. [8].
As stated earlier that tight gas reservoirs require hydraulic fracture treatment to produce the gas at higher rates, it is clear that the hydraulic fracture productivity plays an important role. The productivity of hydraulic fractures largely depends upon the fracture length, fracture height, and fracture permeability [9]. The dependency of these variables on the productivity of hydraulic fractures can be defined by the concept of dimensionless fracture conductivity which is the ratio of ability of fracture of delivering the fluid to the wellbore to the ability of formation to conduit fluid to the created fracture [10]. Other factors include proppant distribution, initial gas composition, non-darcy flow, fracture spacing, hydraulic fracture per stage, drainage area, different wellbore trajectories, and horizontal well length [11-16].

The concept of fold of increase (FOI) is widely used for determining the productivity and performance of hydraulic fractures. It is the ratio of productivity of fractured well to the productivity of unfractured well. McGuire and Sikora [17] presented a graph which discussed the productivity of hydraulic fractured well based on fracture length and fracture conductivity. From that curve, the conclusions can be drawn that the fracture length is the production controlling factor in low permeable reservoir than fracture conductivity whereas fracture conductivity contributes more in high permeable reservoir. Also, the productivity increases with the increasing fracture length. Therefore, it can be deduced that the higher 
value of fracture length results in higher FOI. Many wells, particularly in low-permeability reservoirs, may exhibit much higher (but declining) early time, transient FOI [10].

Apart from the above productivity controlling factors of hydraulic fracture, the geometry of fracture is also a major concern which can cause a drastic change in the productivity of hydraulic fracturing. Hence, it must also be studied with greater depth and concern. The aim of this paper is to understand the effect of different fracture geometries on the productivity of tight gas reservoir. A numerical simulation approach was adopted in which forecasts of different fracture geometries was generated and their impact on gas production rate and gas recovery were evaluated. The variable used to understand different fracture geometries are fracture half-length, fracture height and fracture width.

\section{METHODOLOGY}

\section{Workflow}

To understand the impact on productivity of different type of fracture geometries of a hydraulically fractured well in tight gas reservoir, the following workflow has been adopted:

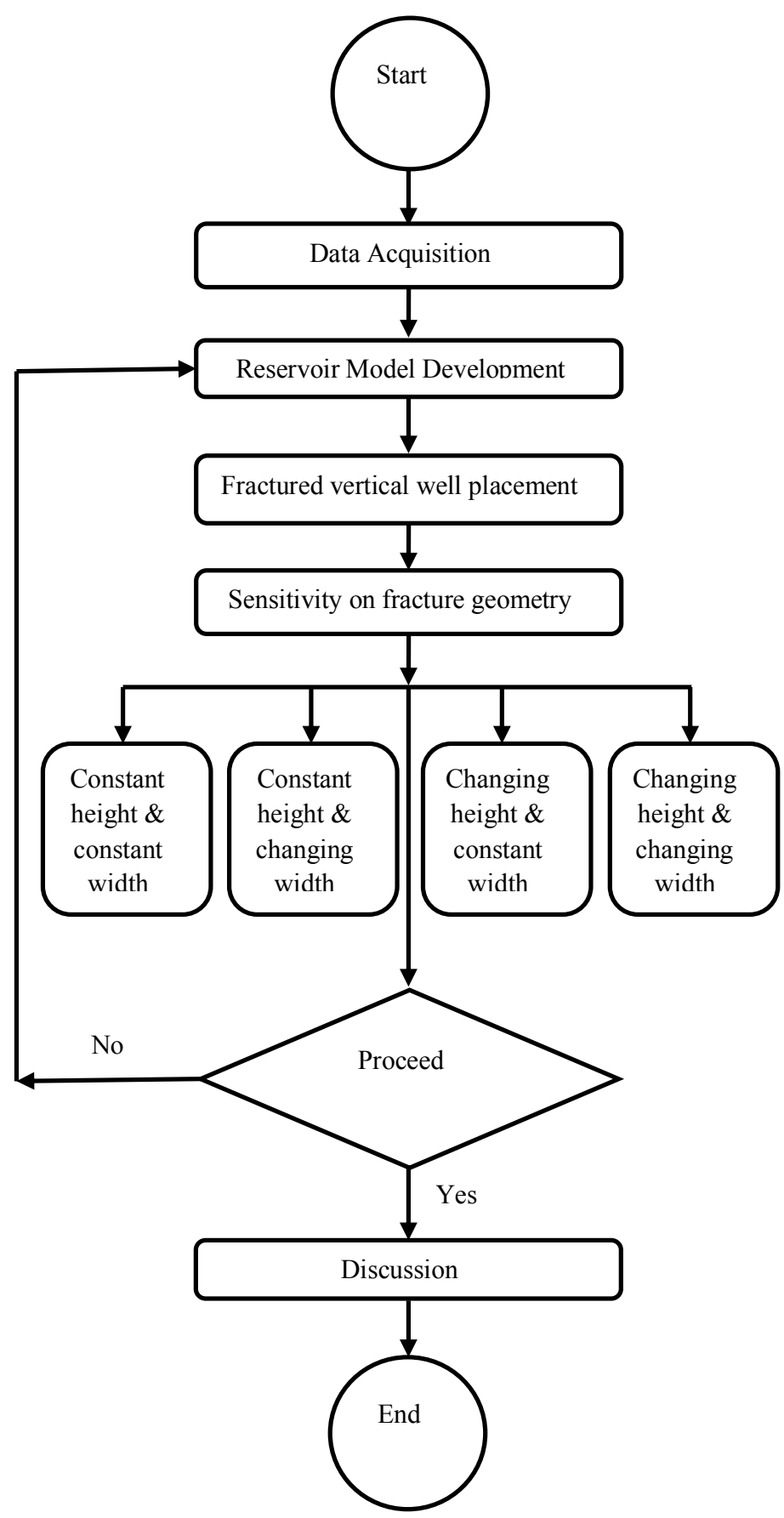

Fig. 1 Workflow for simulation study.

\section{Reservoir simulation and model description}

To understand the effect of change in production from a tight gas sand reservoir by analyzing different type of fracture geometries, a simulation model case is developed by the data from an X-field. Cartesian grids are used for modeling the rock geometry. The reservoir consists of three layers in which the average permeability is assumed to be constant i.e. $0.00363 \mathrm{md}$. The average porosity is taken to be $6 \%$ specifically this case, while the area of the base model is 80 acres.

The reservoir is a two-phase reservoir having gas and water in it. Further, there is no natural fracture in the tight matrix hence single porosity simulation approach has been adopted to develop the base model. In this study, the reservoir is produced from a vertical well with single fracture at the middle layer with flowing bottom hole 
pressure of 1000 psia. The fracture height is taken to be $50 \mathrm{ft}$ and fracture width is taken to be 0.5 inches.

The PVT data set of both gas and water has been generated through default correlation in the simulation software. The change of $\mathrm{z}$-factor with pressure is shown in Figure 2 while the gas formation volume factor response with respect to pressure is shown in Figure 3. The change of gas viscosity at different condition of pressure is shown in Figure 4. Next, the response of gas density with respect to pressure is shown in Figure 5. The water formation volume factor and water viscosity are shown in Figure 6 and Figure 7, respectively.

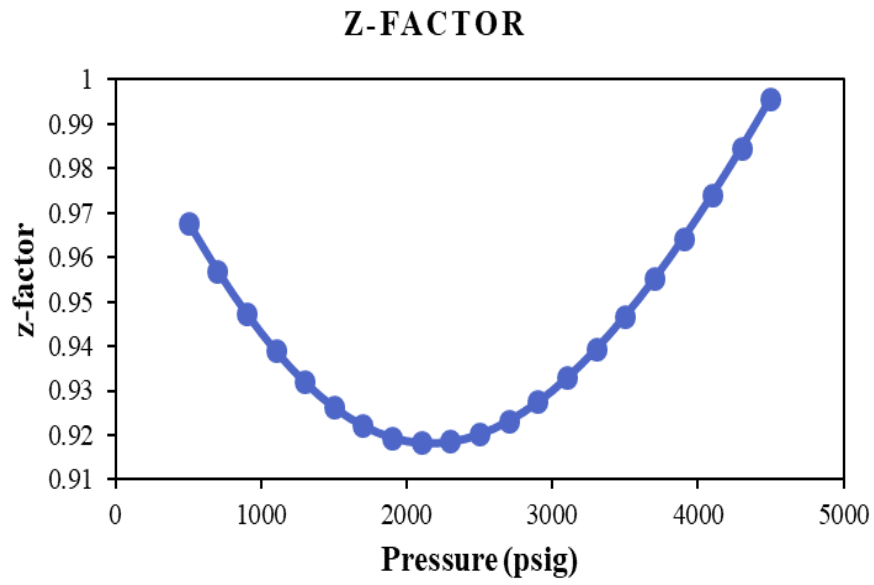

Fig. 2 z-factor changes with respect to pressure.

\section{GAS FORMATION VOLUME FACTOR}

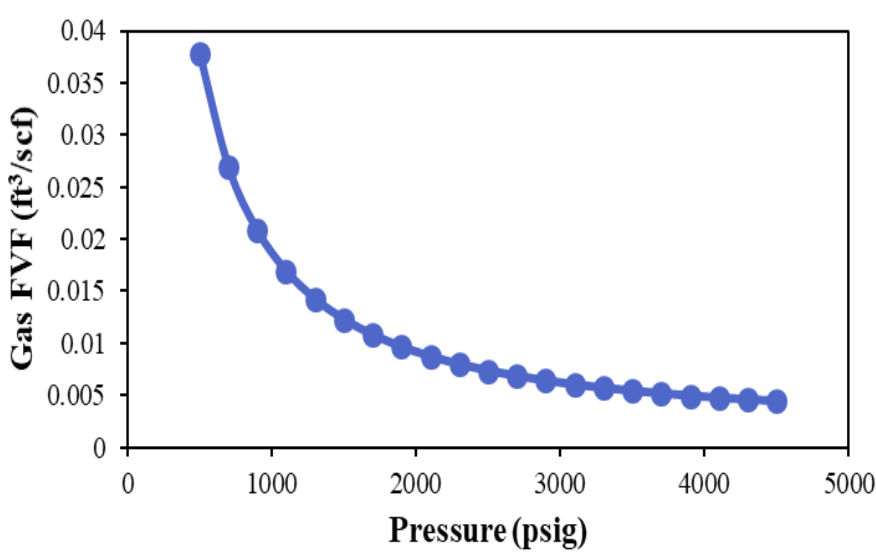

Fig. 3 Gas formation volume factor changes with respect to pressure.

\section{GAS VISCOSITY}

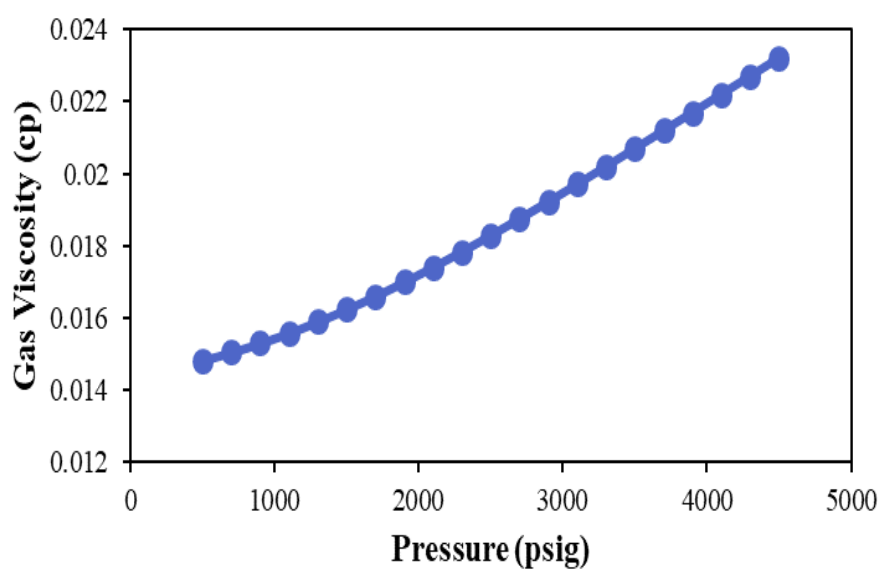

Fig. 4 Gas viscosity changes with respect to pressure.

\section{GAS DENSITY}

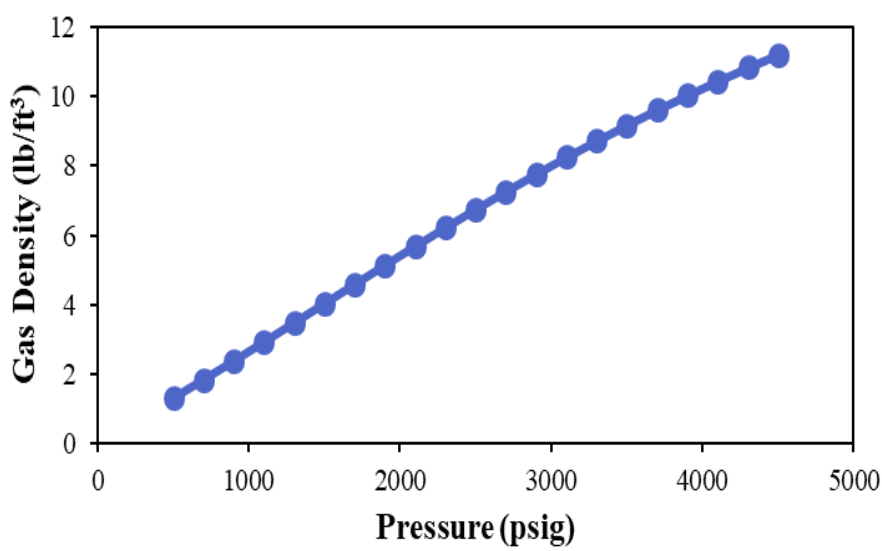

Fig. 5 Gas density changes with respect to pressure.

\section{WATER FORMATION VOLUME FACTOR}

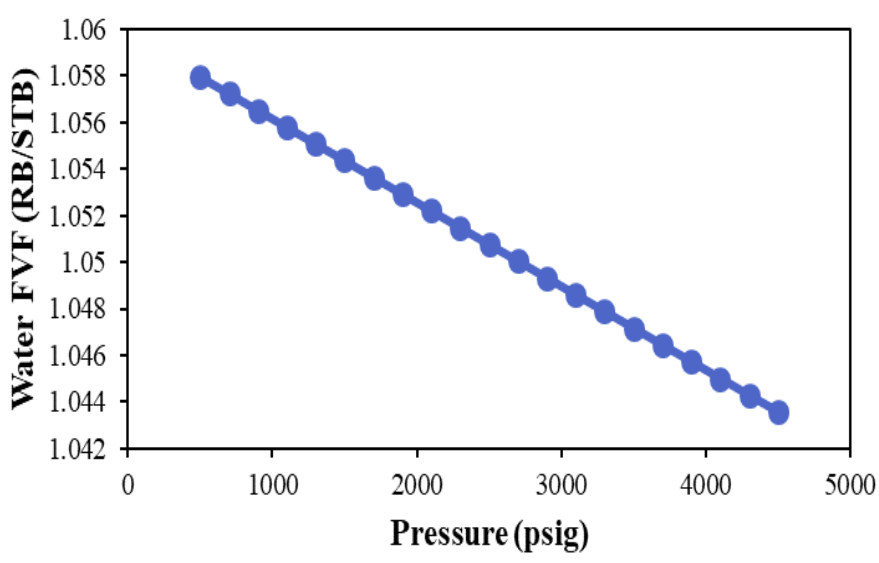

Fig. 6 Water formation volume factor changes with respect to pressure.

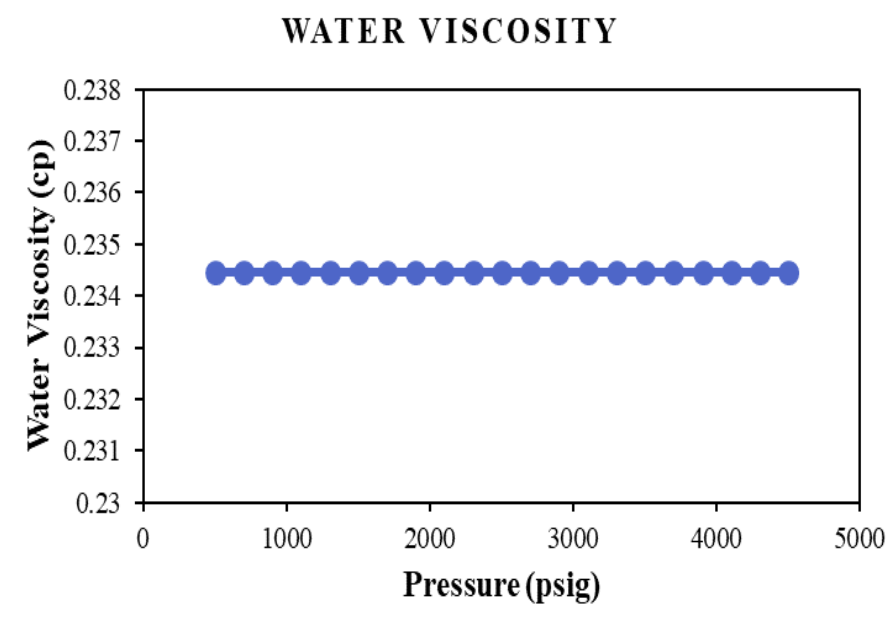

Fig. 7 Water viscosity changes with respect to pressure.

The presented Figures show that the PVT data of gas is drastically changing as compared to water PVT. It is because of the fact that gas is compressible and is very sensitive to pressure changes.

\section{Calculation of relative permeability}

The relative permeability data is a mandatory piece information to be inputted in the simulation software to describe the flow of fluid in tight gas media. Because of the lack of availability of relative permeability data in tight gas sand reservoir, the relative permeability curves are generated analytically by solving Brooks and Corey 
equation in water gas system. The Brooks and Corey equation in a water gas system is given as follows [18]:

$$
\begin{aligned}
& k_{r w}=\left[S_{w}^{*}\right]^{\left(\frac{2+31}{1}\right)} \\
& k_{r n w}=\left(1-S_{w}^{*}\right)^{2}\left[1-S_{w}^{*}\left(\frac{2+1}{i}\right)\right] \\
& S_{w}^{*}=\frac{S_{w}-S_{w r}}{1-S_{w r}}
\end{aligned}
$$

where

$\lambda=$ Pore structure characteristic which is the slope of $\mathrm{Sw}^{*}$ versus $\mathrm{Pc}$ in a log-log plot;

$\mathrm{K}_{\mathrm{rw}}=$ Relative permeability to wetting phase (water);

$\mathrm{K}_{\text {nrw }}=$ Relative permeability to non-wetting phase (gas);

$\mathrm{S}_{\mathrm{w}}=$ Wetting phase saturation (water saturation);

$\mathrm{S}_{\mathrm{wr}}=$ Residual wetting phase saturation (residual water saturation).

The irreducible water saturation for sandstone reservoir is taken to be $30 \%$ based on desorption measurement as suggested by Ward and Morrow [19]. The generated relative permeability curves are shown in Figure 8 .

\section{RELATIVE PERMEABILITY CURVE}

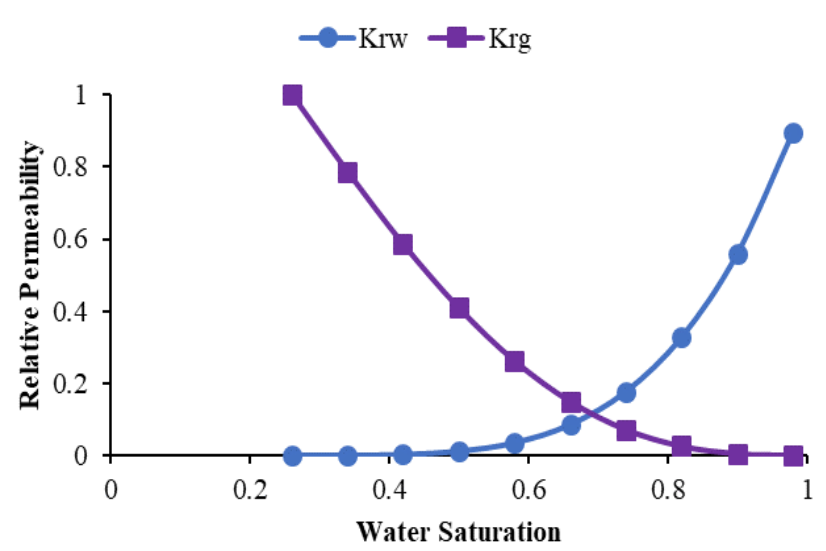

Fig. 8 Relative permeability curves based on Brooks and Corey equation.

\section{CASE SCENARIOS}

To understand the effect of different hydraulic fracture geometries on the productivity of tight gas reservoir, sensitivity has been observed under the following four cases:

1. Constant fracture height and constant fracture width;

2. Constant fracture height and changing fracture width;

3. Changing fracture height and constant fracture width;

4. Changing fracture height and changing fracture width.

These cases are analyzed based on the production rate, cumulative production, recovery factor, and pressure depletion. Ultimately, the best possible hydraulic fracture geometry is discussed. The productivity of these cases is obtained at fracture half-lengths of 100 $\mathrm{ft}, 200 \mathrm{ft}, 300 \mathrm{ft}, 400 \mathrm{ft}$, and $500 \mathrm{ft}$. These fracture half-lengths can be achieved by any fracturing fluid depending upon the suitability of the fluid with the formation. In this study, the properties of water-based fracturing fluid are used. The fracture geometry at constant fracture height and constant fracture width is shown in Figure 9. The fracture geometry at constant fracture height and changing fracture width is shown in Figure 10. The fracture geometry at changing fracture height and constant fracture width is shown in Figure 11. The fracture geometry at changing fracture height and changing fracture width is shown in Figure 12. The changing color from blue to red shows changing fracture width with blue showing minimum width and red showing maximum fracture width. The fracture width is controlled by the distribution of proppants in the fracture. Low proppant distribution results in low fracture width and high proppant distribution results in high fracture width. The sand-based proppant properties are used in this study for hydraulic fracturing simulation.

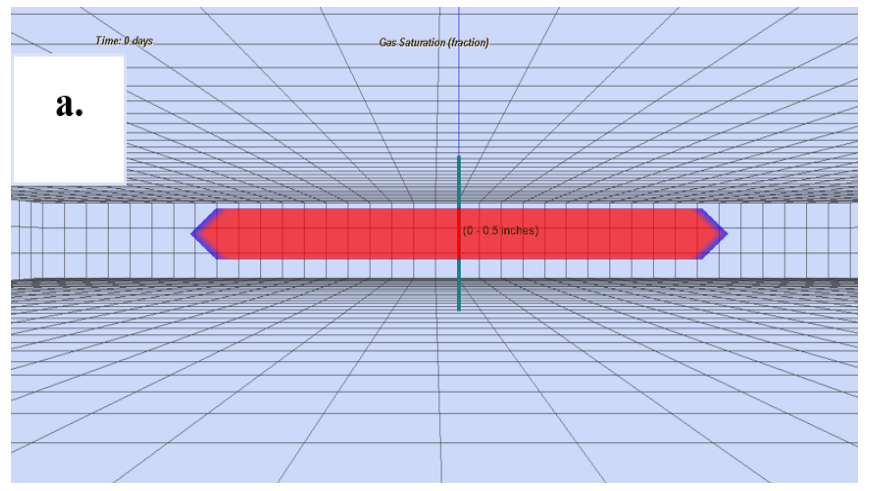

Fig. 9 Fracture geometry at constant fracture height and constant fracture width.

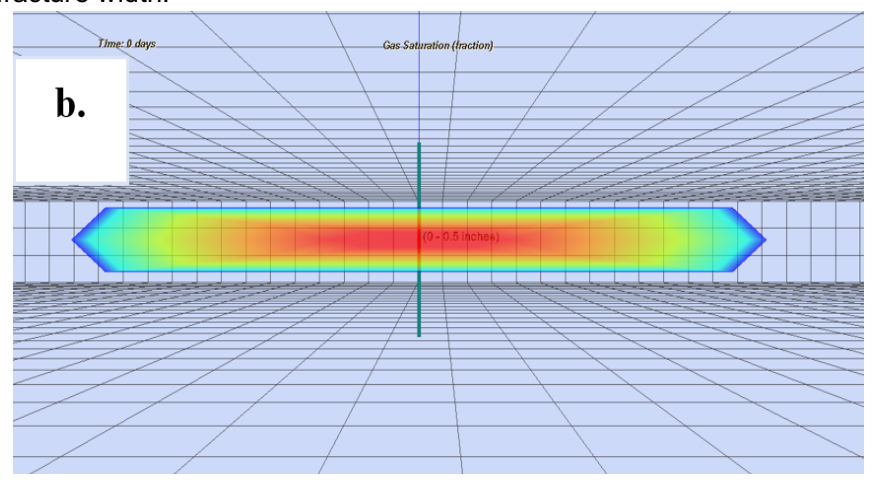

Fig. 10 Fracture geometry at constant fracture height and changing fracture width

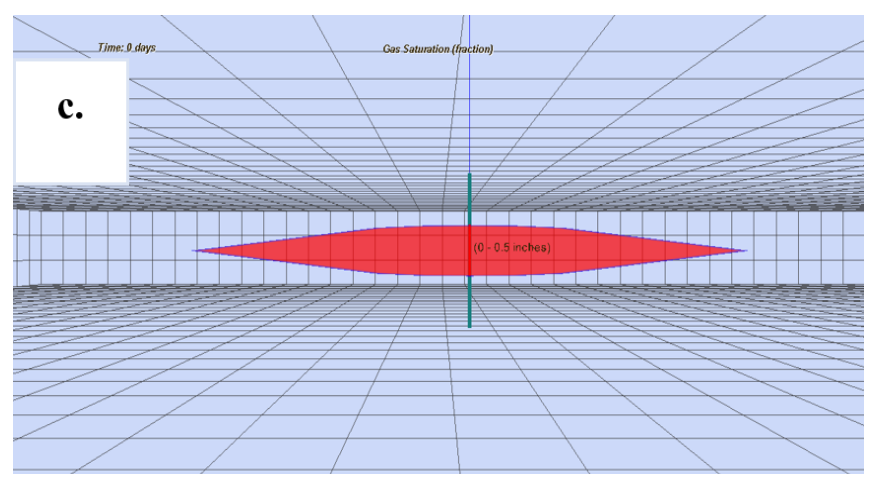

Fig. 11 Fracture geometry at changing fracture height and constant fracture width.

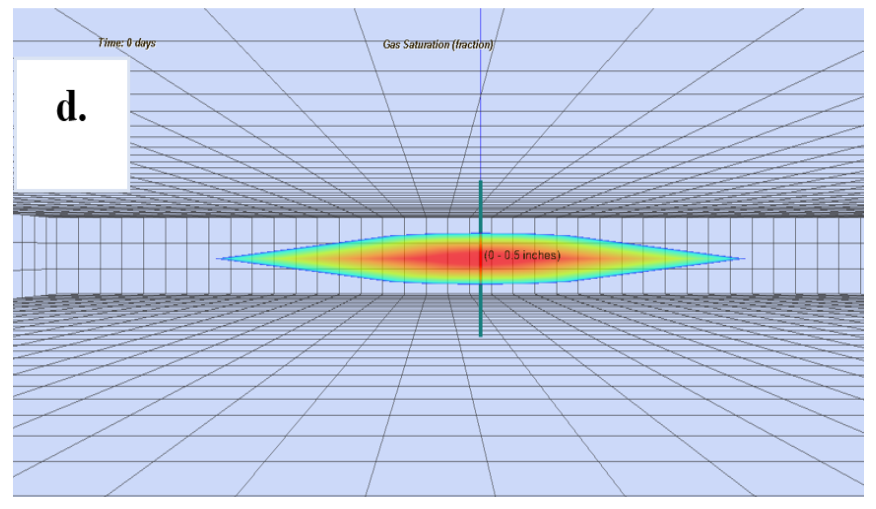

Fig. 12 Fracture geometry at changing fracture height and changing fracture width. 


\section{RESULTS AND DISCUSSION}

Case 1: Constant fracture height and constant fracture width

In the first case, the fracture height and the fracture width are taken to be constant. The gas production rates along with pressure depletion profile is shown in Figure 13.

\section{CASE 1: FRACTURE HALF-LENGTHS}

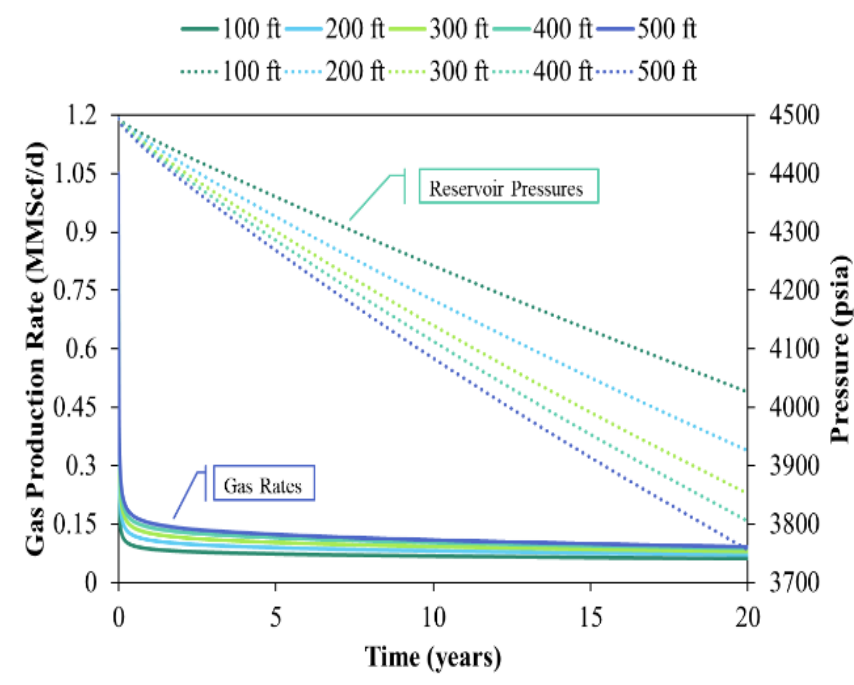

Fig. 13 Case 1 - Gas production rate.

The cumulative gas production along with pressure depletion profile is shown in Figure 14.

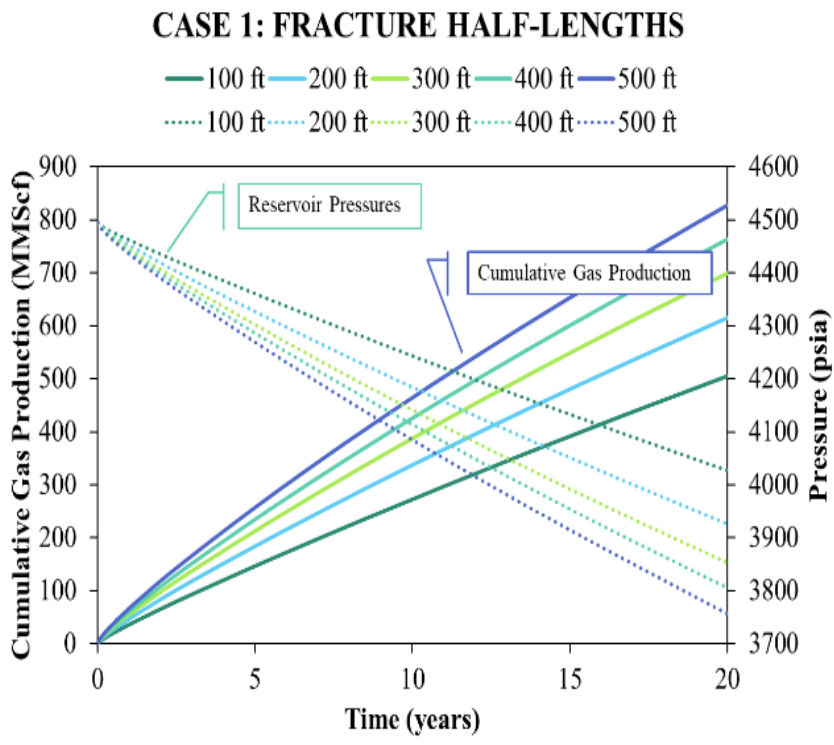

Fig. 14 Case 1 - Cumulative gas production.

As discussed earlier, high fracture half-length results in high production. This behavior is also evident in Figure 13 and Figure 14 that with the increase in fracture half-length the production is increasing. This behavior is further justified from the pressure depletion profile that for higher fracture half-lengths, there is more pressure depletion. The cumulative productions for $100 \mathrm{ft}, 200 \mathrm{ft}, 300$ $\mathrm{ft}, 400 \mathrm{ft}$, and $500 \mathrm{ft}$ of fracture half-length are $506 \mathrm{MMSCF}, 616$ MMSCF, $700 \mathrm{MMSCF}, 764 \mathrm{MMSCF}$, and $827 \mathrm{MMSCF}$, respectively. The early drop in gas production rate in the reservoir is due to the transient flow period. Later, the flow reaches to stabilized rates. Noted that with the increase in fracture half-length, the production does increase but the increase in production is not linear. In order to better understand this phenomenon, plots of recovery factor at different fracture half-lengths (Figure 15) and recovery factor versus fracture half-length (Figure 16) have been plotted.

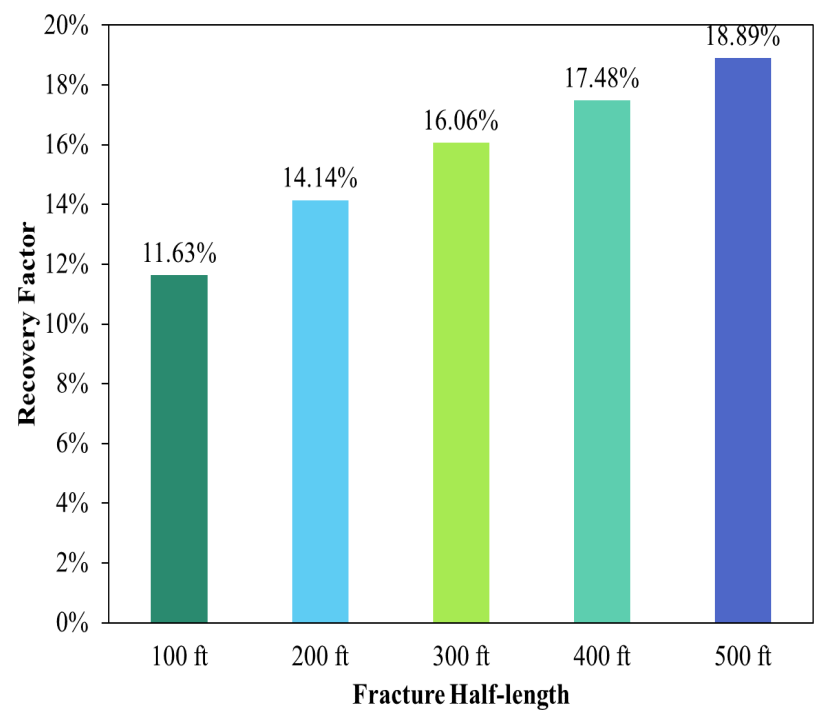

Fig. 15 Case 1 - Recovery factor at different fracture half-lengths.

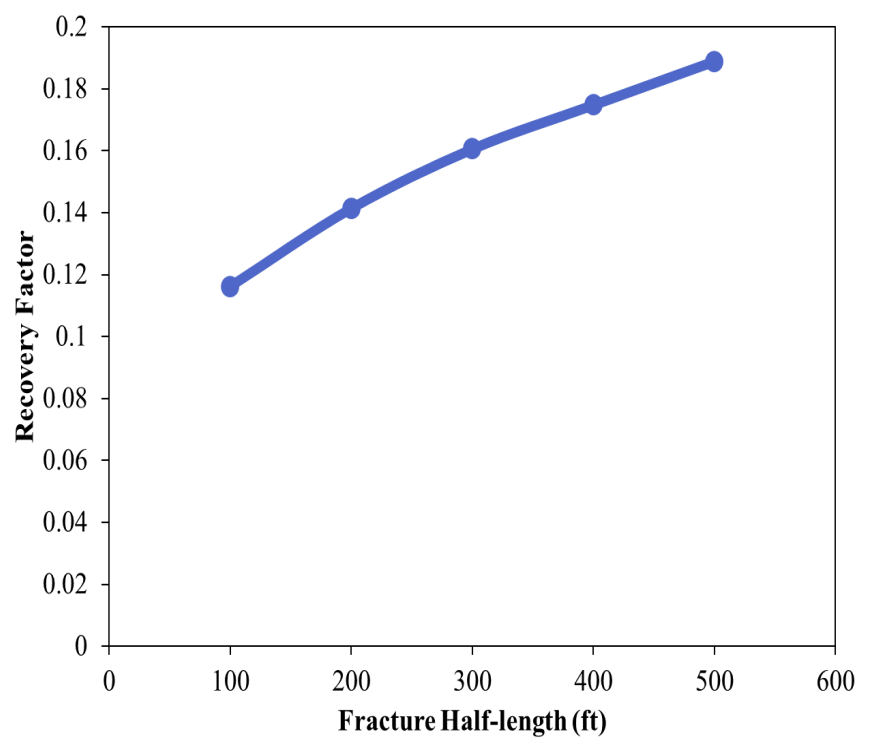

Fig. 16 Case 1 - Recovery factor versus fracture half-length.

It can be seen in Figure 15 that from $100 \mathrm{ft}$ to $200 \mathrm{ft}$, there is an increment in recovery of $2.51 \%$. From 200 to $300 \mathrm{ft}$, the increment is $1.92 \%$. Moving from $300 \mathrm{ft}$ to $400 \mathrm{ft}$, the increment is $1.42 \%$ and from $400 \mathrm{ft}$ to $500 \mathrm{ft}$, the increment is $1.41 \%$. This explains the presence of a curve in recovery factor versus fracture half-length plot and not a straight line. Also, the pressure drop in the reservoir may be getting closer and closer to pressure drop in the hydraulic fracture with increasing fracture half-length which causes the effect described earlier.

\section{Case 2: Constant fracture height and changing fracture width}

In this case, the fracture height is taken to be constant, however, the fracture width is changing having minimum width at the edges of the fracture and maximum width at the center of fracture. The range of fracture width is between 0 to 0.5 inches. The changing width is taken in order to define a more realistic geometry since continuous injection of fracturing slurry causes the fracture to increase in width and causing the fracture to balloon [20]. At the end of fracturing operation, the closure pressure of the formation causes the fracture to 
close. This means that more proppant accumulates at the center which maintains a wider fracture while fracturing and at the tip of fracture the amount of accumulation of proppant is quite low which causes the width of fracture to be at minimum. The gas production rate response is shown in Figure 17, while the cumulative gas production is shown in Figure 18.

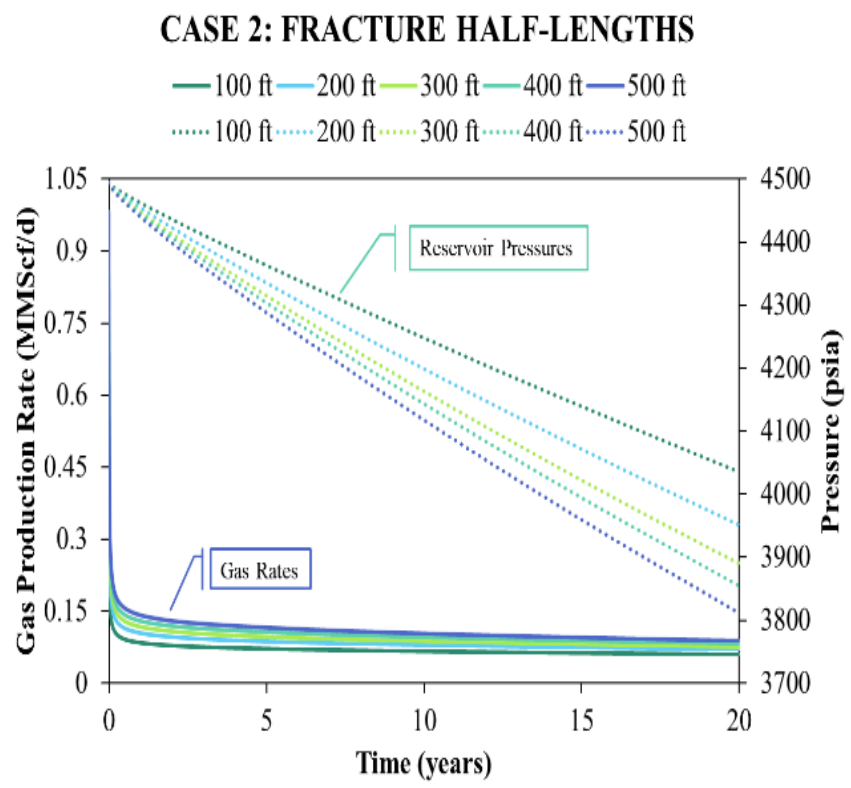

Fig. 17 Case 2 - Gas production rate.

\section{CASE 2: FRACTURE HALF-LENGTHS}

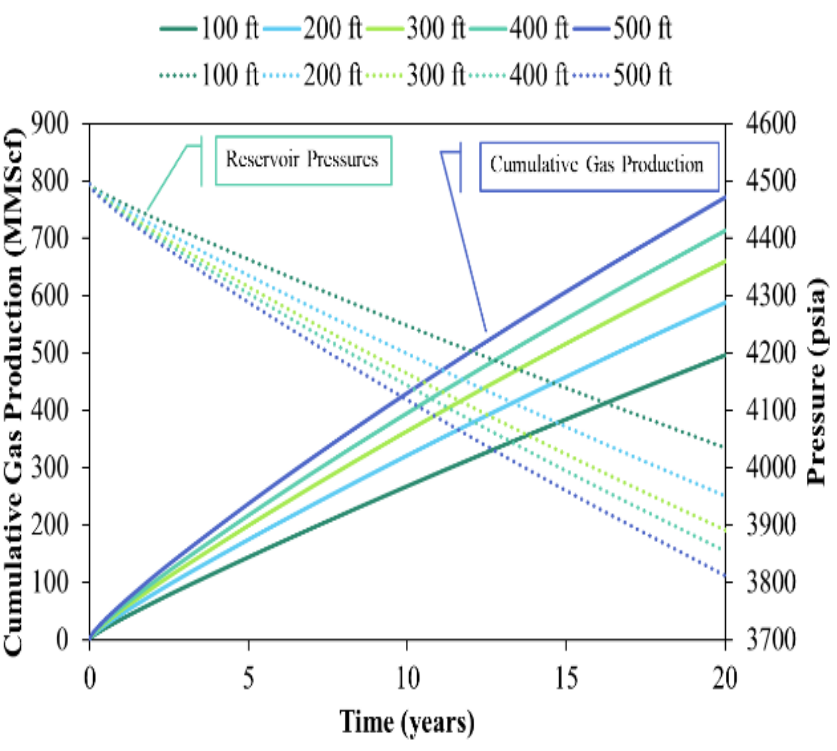

Fig. 18 Case 2 - Cumulative gas production.

Similar to the previous case, the production is increasing with increasing fracture half-length. The pressure depletion in Figure 17 and Figure 18 also justifies that there is higher reservoir pressure depletion which corresponds to higher productivity. However, the production in this case is lower than that observed in case 1 . The cumulative productions obtained for $100 \mathrm{ft}, 200 \mathrm{ft}, 300 \mathrm{ft}, 400 \mathrm{ft}$, and $500 \mathrm{ft}$ are $497 \mathrm{MMSCF}, 589 \mathrm{MMSCF}, 660 \mathrm{MMSCF}, 713 \mathrm{MMSCF}$, and $771 \mathrm{MMSCF}$, respectively. This decline in production is due to the fact that the width keeps on decreasing from center of the fracture to the tip of fracture which causes a lower fracture volume as compared to the volume in case 1 . Noted that the maximum fracture width is 0.5 inches which is actually the base width of case 1 . The recovery factor at different fracture half-lengths (Figure 19) and recovery factor versus fracture half-length curves (Figure 20) are also plotted in this case to understand the productivity change with varying fracture half-lengths.

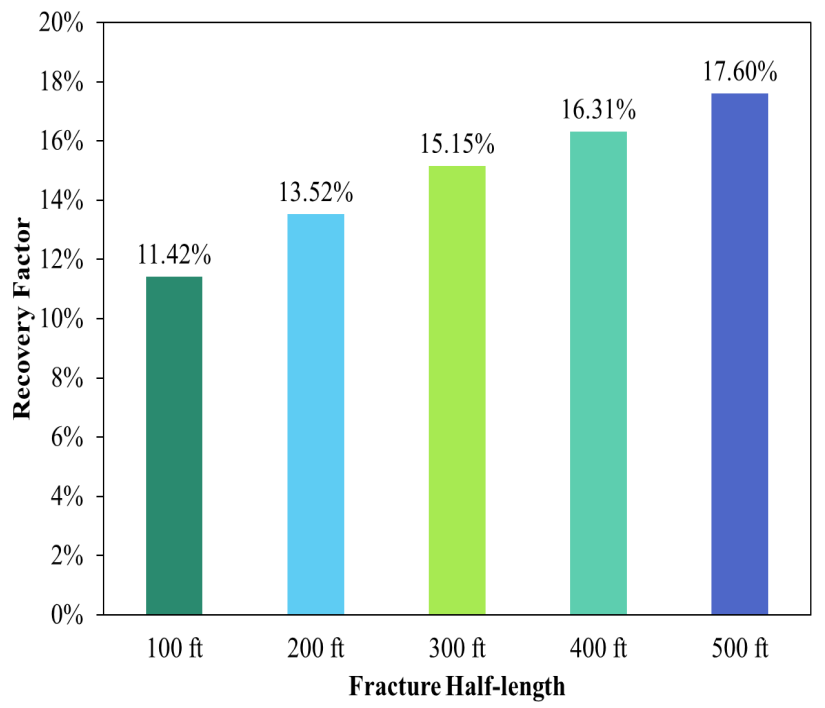

Fig. 19 Case 2 - Recovery factor at different fracture half-lengths.

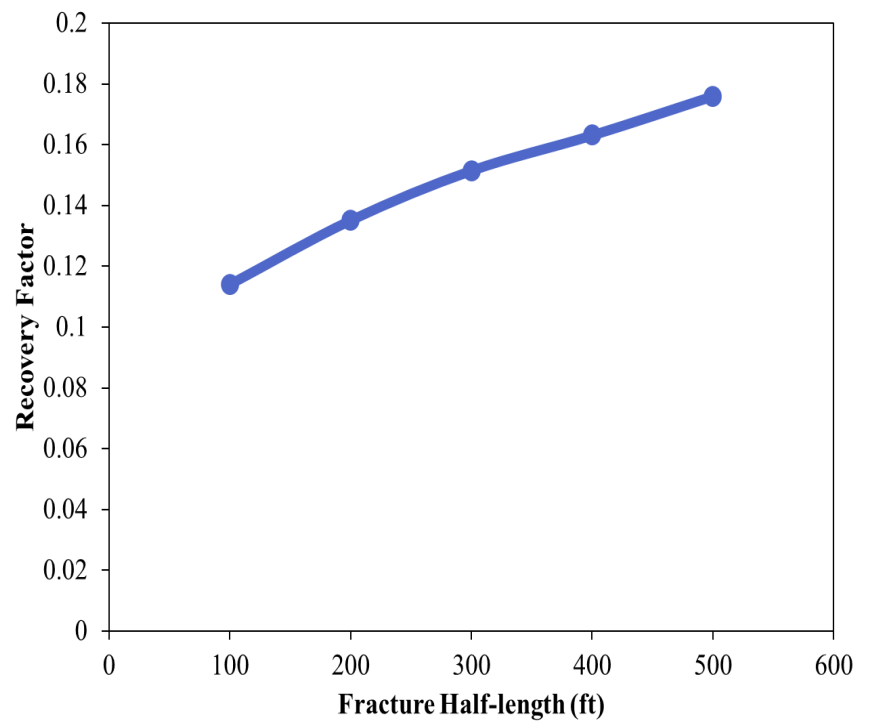

Fig. 20 Case 2 - Recovery factor versus fracture half-length.

The increment in recovery in this case is also lesser than that in case 1 . From $100 \mathrm{ft}$ to $200 \mathrm{ft}$, the increment in recovery is $2.1 \%$. The increments from $200 \mathrm{ft}$ to $300 \mathrm{ft}, 300 \mathrm{ft}$ to $400 \mathrm{ft}$, and $400 \mathrm{ft}$ to $500 \mathrm{ft}$ are $1.63 \%, 1.16 \%$, and $1.29 \%$, respectively. Here, the increase in recovery factor while increasing the fracture half-length is not a linear one. It is also a curve since the pressure depletion in the reservoir gets much closer to hydraulic fracture pressure drop.

\section{Case 3: Changing fracture height and constant fracture width}

In most cases, the hydraulic fracture height is restricted because of geological setting and in situ stresses prevailing the formation [21, 22]. Keeping this concept, a case has been studied in which the fracture height is changing with increasing fracture half-length however the fracture width is assumed to be constant. The sensitivity at different fracture half-lengths is performed to study the production response from such geometry of fracture. The gas production rate obtained after simulating this case is shown in Figure 21. The cumulative gas production is presented in Figure 22. The pressure 
profile is also plotted in the gas production rate graph and cumulative gas production graph.

\section{CASE 3: FRACTURE HALF-LENGTHS}

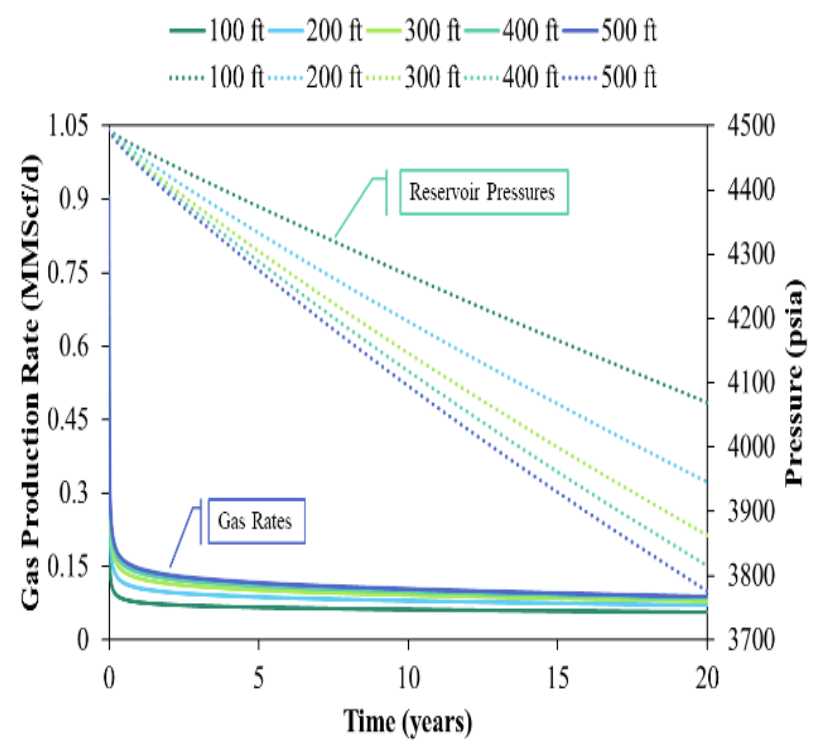

Fig. 21 Case 3 - Gas production rate.

\section{CASE 3: FRACTURE HALF-LENGTHS}

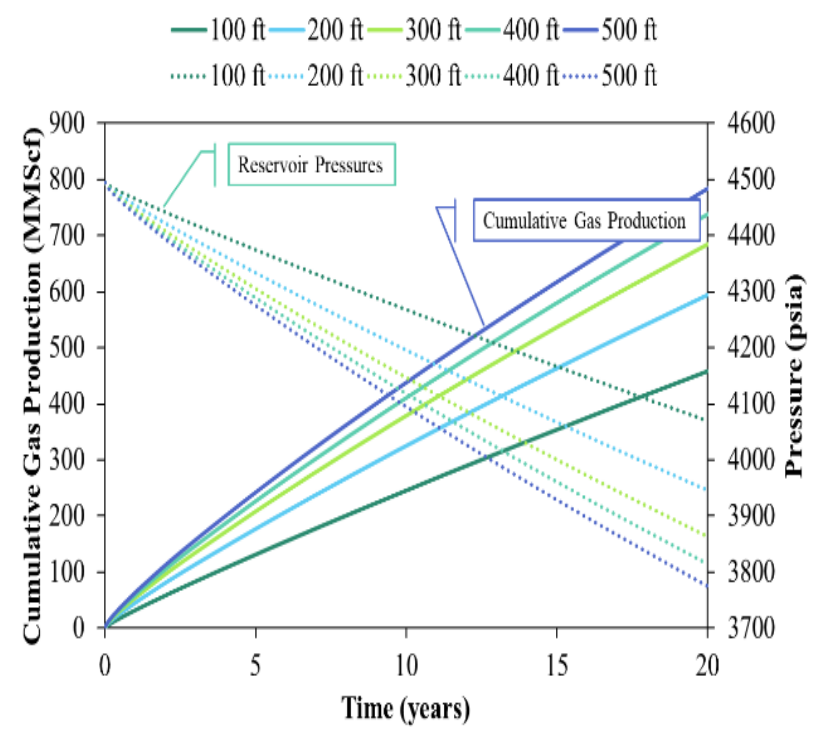

Fig. 22 Case 3 - Cumulative gas production.

Similar trend is observed in this case where increasing fracture half-length along with changing fracture height results in increased production. Again, high pressure depletion is subjected to increased fracture half-length in this case. The cumulative production obtained for $100 \mathrm{ft}, 200 \mathrm{ft}, 300 \mathrm{ft}, 400 \mathrm{ft}$, and $500 \mathrm{ft}$ is $459 \mathrm{MMSCF}, 594$ MMSCF, 685 MMSCF, 737 MMSCF, and 783 MMSCF, respectively. Comparing to case 1 , the production obtained in this case is lower than case 1 . This is because in case 1, the fracture volume is greater than case 3 since in case 1 the fracture dimensions i.e. length, width, and height are taken to be constant and their values are maximum values. However, in this case the fracture height close to well is same as that of in case 1 but it keeps on decreasing as fracture goes deeper into the formation. This is a result of high in situ stress which confines the fracture height.

The recovery factor at different fracture half-lengths and recovery factor versus fracture half-length is also plotted. They are shown in Figure 23 and Figure 24, respectively.

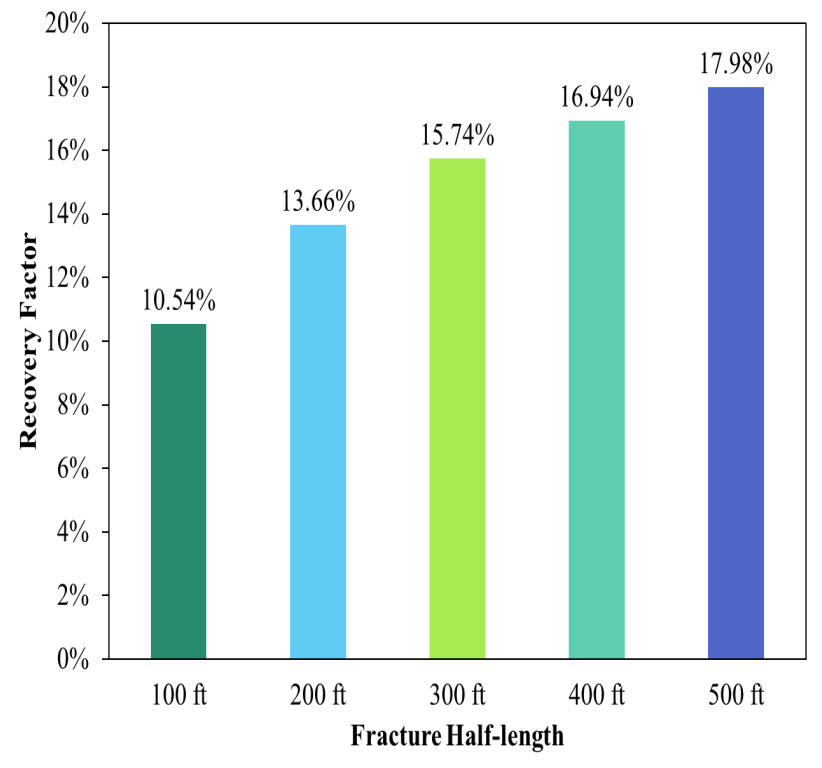

Fig. 23 Case 3-Recovery factor at different fracture half-lengths.

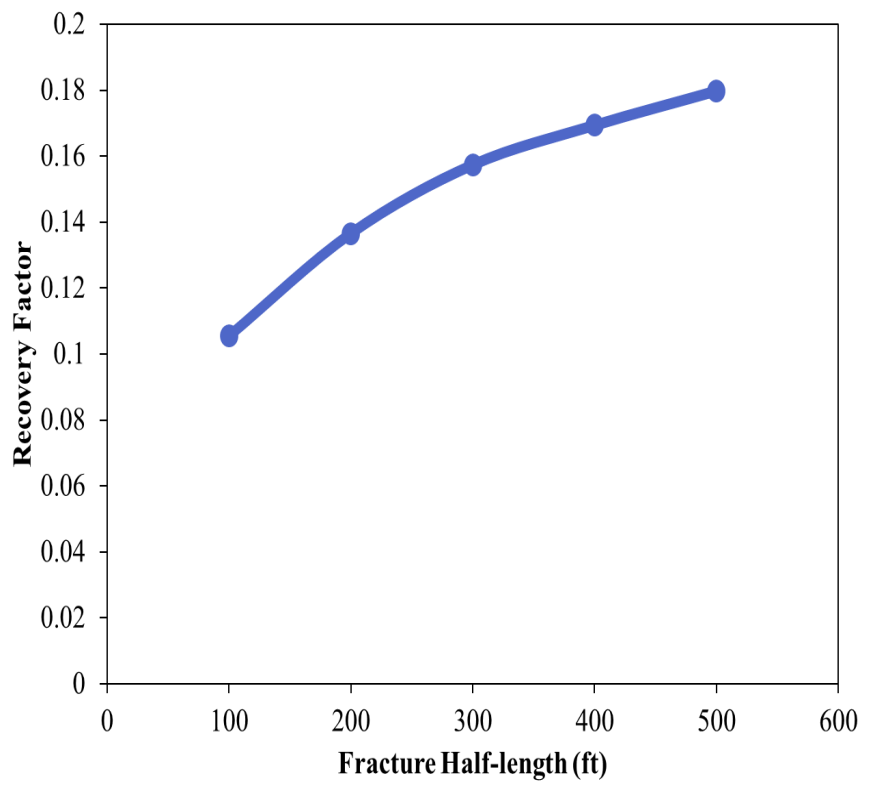

Fig. 24 Case 3 - Recovery factor versus fracture half-length.

This response obtained from Figure 24 clearly shows that the increment of production with fracture half-length in this case is not a linear one. Hence, at some point in the life of reservoir, the reservoir full capacity to deliver the gas into the fracture may reach, at high fracture half-length values, which results in a low increase in recovery of gas at high values of fracture half-length.

\section{Case 4: Changing fracture height and changing fracture width}

Since fracture height and fracture width both are affected by the in situ stresses, the scenario has been studied in which both fracture height and fracture width changes simultaneously as fracture propagates in the formation. The gas production rates and cumulative gas production curves has been generated which are shown in Figure 25 and Figure 26, respectively. 


\section{CASE 4: FRACTURE HALF-LENGTHS}

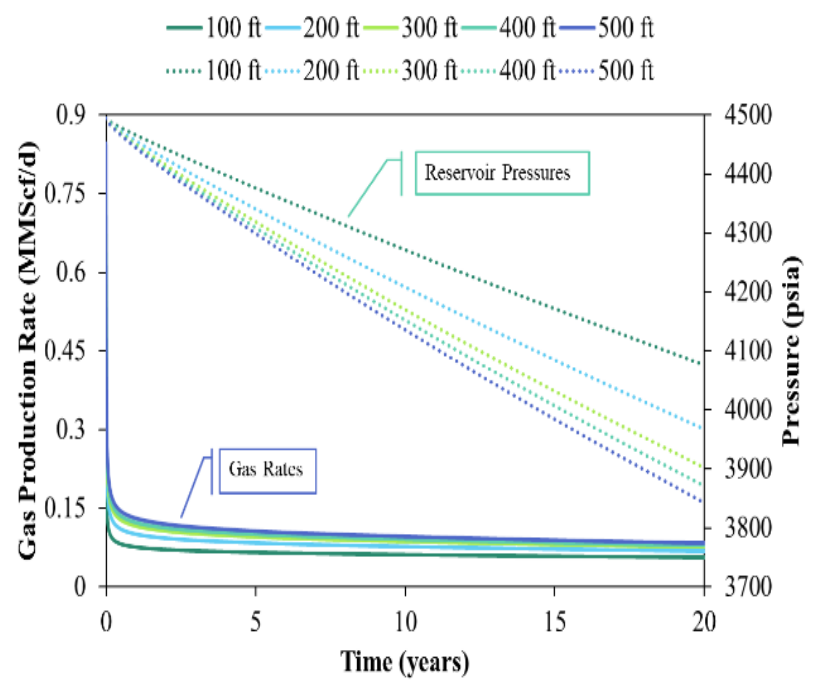

Fig. 25 Case 4 - Gas production rate.

\section{CASE 4: FRACTURE HALF-LENGTHS}

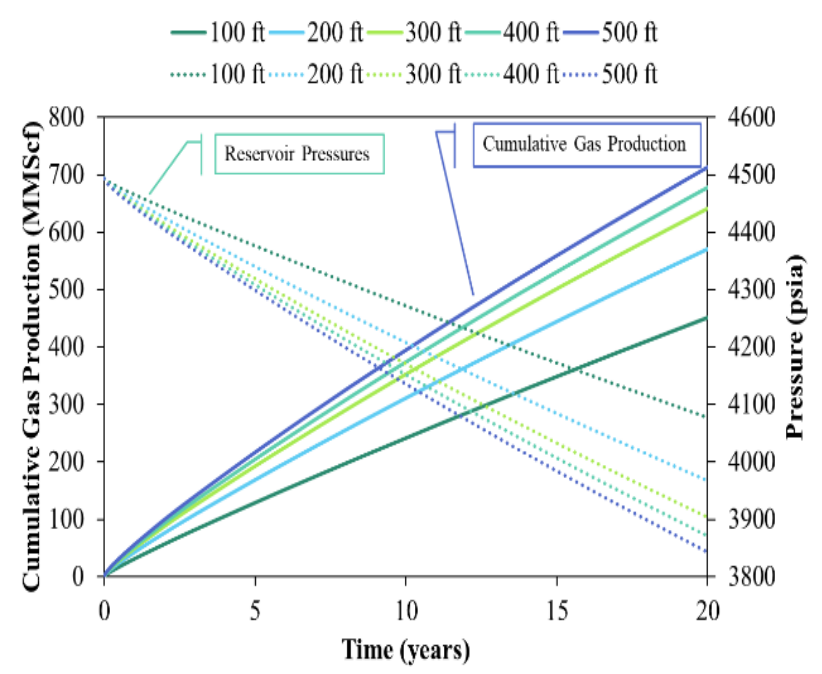

Fig. 26 Case 4 - Cumulative gas production.

The recovery factor at different fracture half-length values and recovery factor versus fracture half-length curves have been generated to understand the effect of changing height and changing width during the fracture propagation on productivity of hydraulic fracture. They are shown in Figure 27 and Figure 28, respectively.

The cumulative productions obtained for $100 \mathrm{ft}, 200 \mathrm{ft}, 300 \mathrm{ft}, 400$ $\mathrm{ft}$, and $500 \mathrm{ft}$ are $452 \mathrm{MMSCF}, 571 \mathrm{MMSCF}, 642 \mathrm{MMSCF}, 679$ MMSCF, and 714 MMSCF, respectively. The recovery factor increment from different half-lengths are as follows: $100 \mathrm{ft}$ to $200 \mathrm{ft}$ is $2.74 \%$, the increment from $200 \mathrm{ft}$ to $300 \mathrm{ft}$ is $1.62 \%$, the increment from $300 \mathrm{ft}$ to $400 \mathrm{ft}$ is $0.85 \%$, and the increment from $400 \mathrm{ft}$ to $500 \mathrm{ft}$ is $0.78 \%$. This increased production shows that regardless of the case, production of gas is controlled by fracture dimensions i.e. fracture length, fracture height and fracture width. In other words, we can say that it is controlled by fracture volume.

\section{Comparison of all cases}

After analyzing all the above cases separately, an analysis has been carried to compare the behavior of all fracturing geometries. The cumulative production, recovery factor, and recovery factor versus fracture half-length plots has been compared to understand the impact of fracture geometry on the productivity of hydraulic fracture.

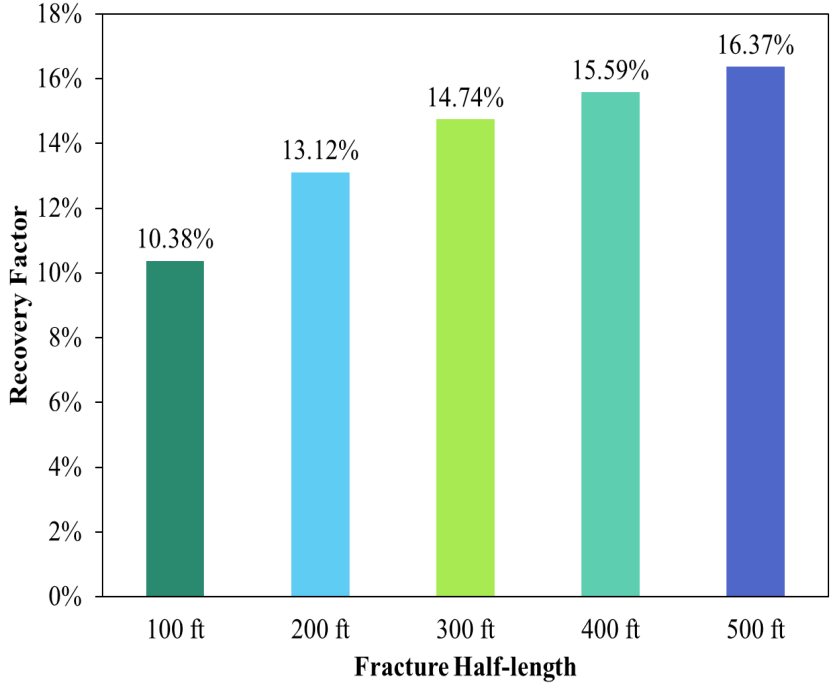

Fig. 27 Case 4 - Recovery factor at different fracture half-lengths.

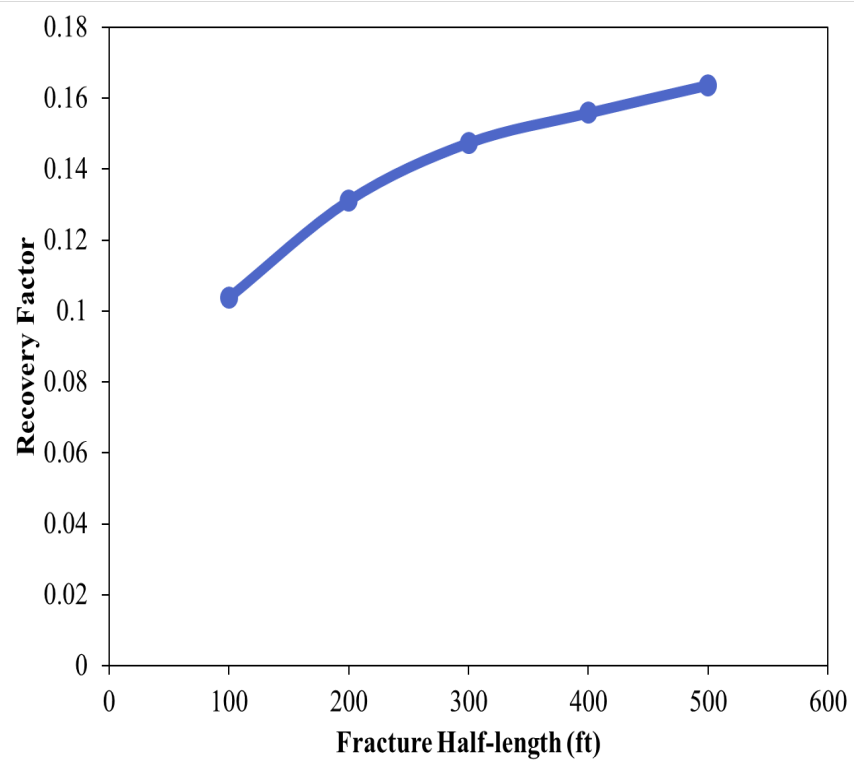

Fig. 28 Case 4 - Recovery factor versus fracture half-length.

The cumulative production comparison is shown in Figure 29, while the recovery factor comparison is shown in Figure 30. It can be seen from Figure 29 and Figure 30 that the fracture geometry with constant height and constant width provides high recoveries than other cases.

Figure 31 which shows the recovery factor versus fracture halflength also justifies the above statement. The case 1 scenario tops the chart with high productivity and case 4 results comes at last in terms of productivity obtained from fracture. In case 2 and case 3 , there is a certain abnormality in productivity as seen in Figure 31. Case 2 productivity is higher than case 3 when the fracture half-length is 100 $\mathrm{ft}$. However, the case 3 productivity starts to jump with higher increment in recovery than case 2 and passes the recovery of case 2 at $200 \mathrm{ft}$. This shows that for constant height and changing width the recovery obtained is higher for low fracture half-lengths, however for high fracture half-lengths changing height and constant width contributes more to the production.

This behavior can be understood better from Figure 10 in the case scenario section. It can be observed from Figure 10 that as the fracture goes deep into the formation, the fracture width starts to decrease, causing more closure to fracture which results in lesser productivity increase as compared to case 3 in which the width is constant over the whole fracture half-length. This high closure of fracture can result in 
less volume of fracture to contribute significantly to production as compared to case 3 . If the width of the fracture in case 2 does not get low because of high closure stresses, then the case 2 productivity can also be higher for high fracture half-lengths as compared to case 3 .

\section{CUMULATIVE GAS PRODUCTION COMPARISON}

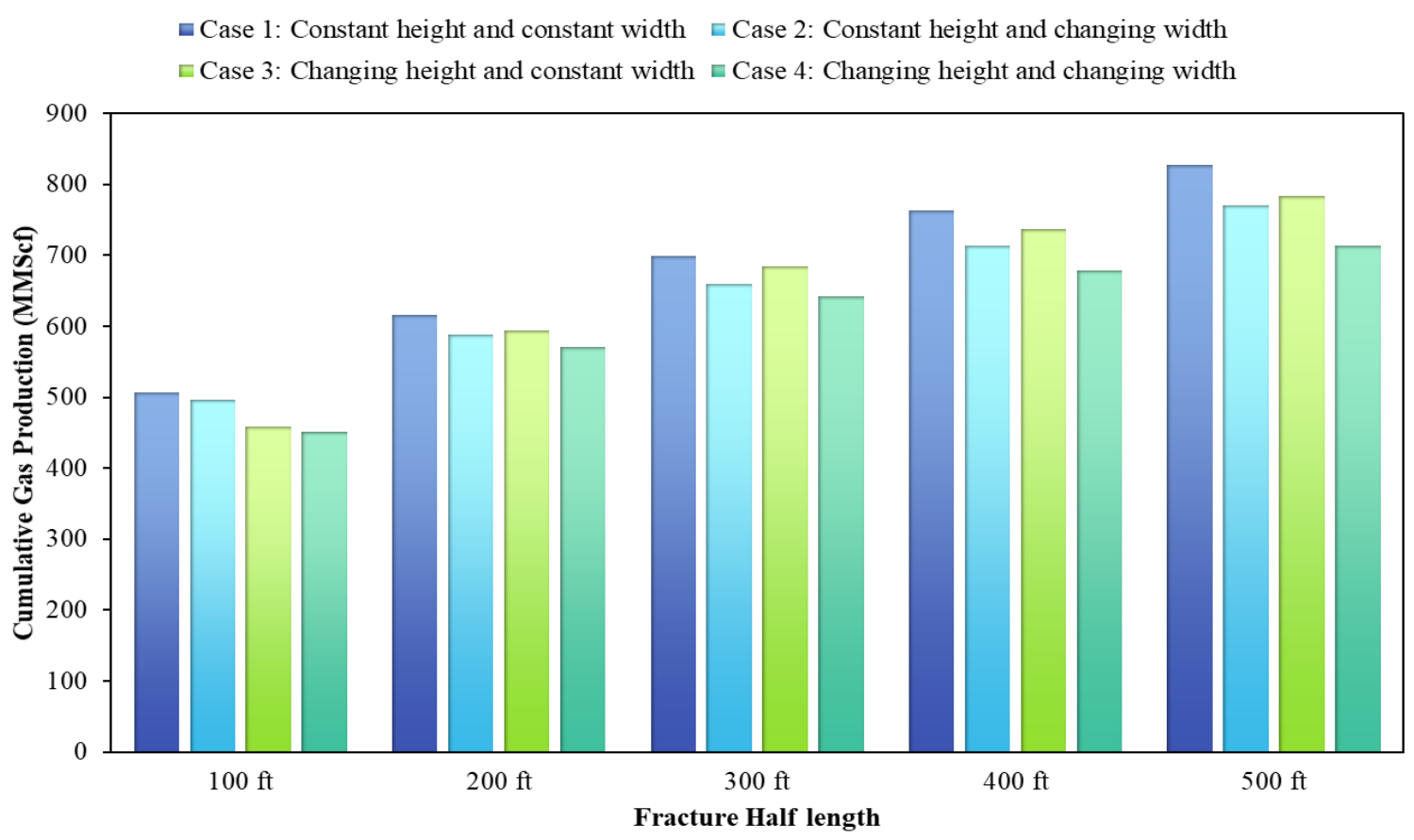

Fig. 29 Cumulative gas production comparison of all cases.

\section{RECOVERY FACTOR COMPARISON}

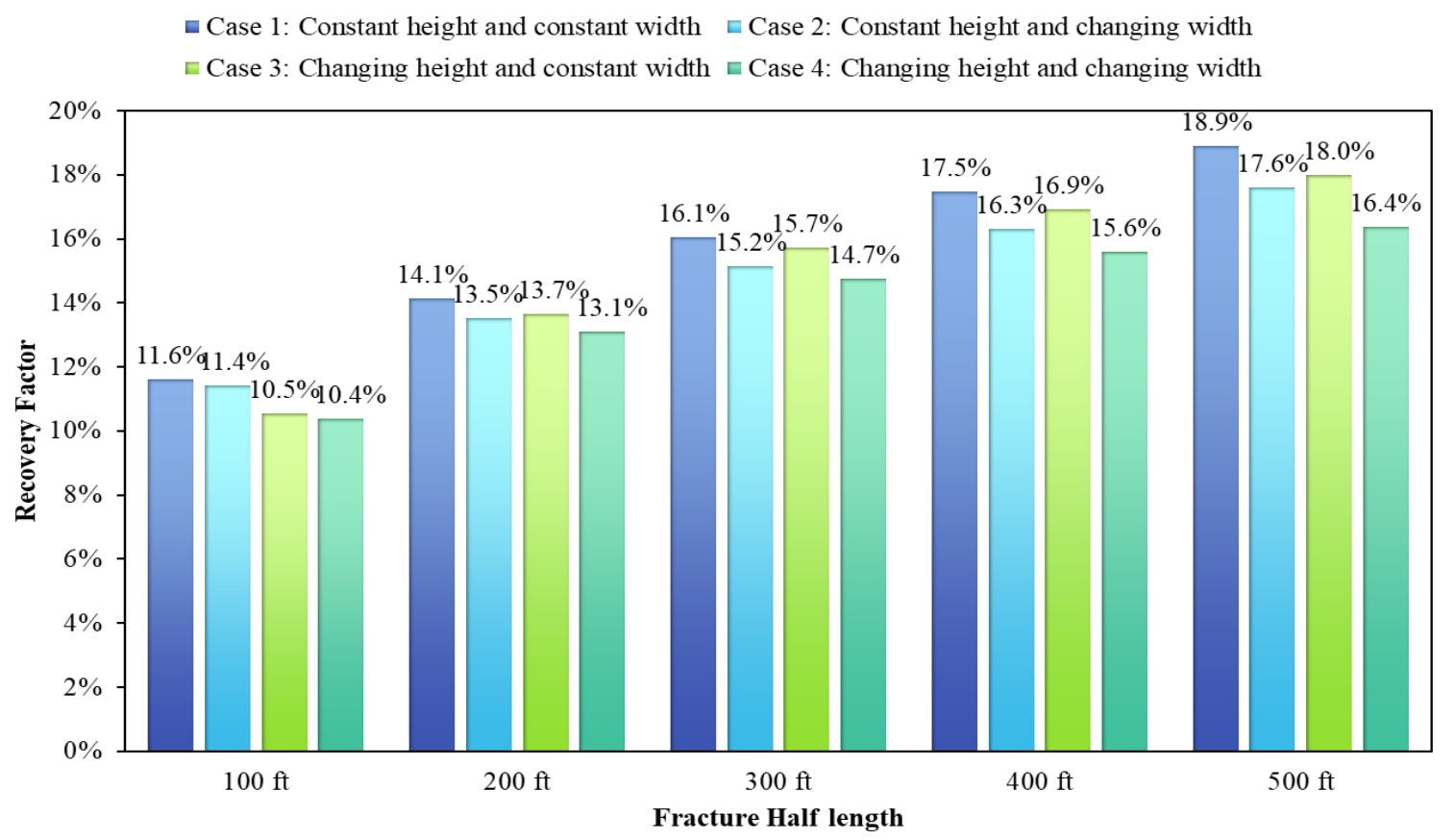

Fig. 30 Recovery factor comparison of all cases. 


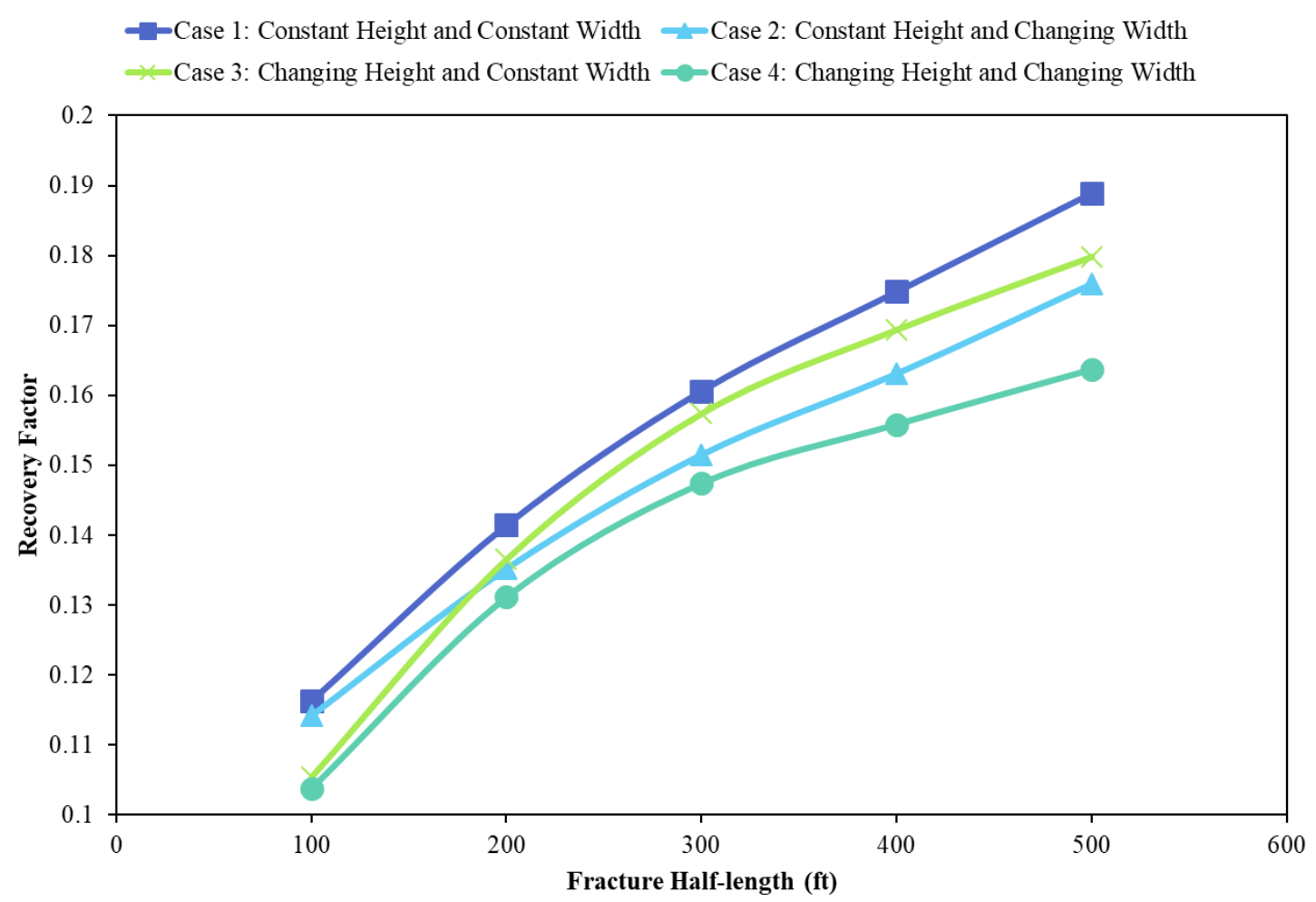

Fig. 31 Recovery factor versus fracture half-length comparison of all cases.

Furthermore, in all cases the effect of fracture half-length is quite evident. Increasing the fracture half-length increases the fracture productivities in any scenario. However, the increment rates vary depending upon the geometry of the fracture in the formation as shown in Figure 31.

The above comparison of different fracture geometries suggests that keeping the fracture height and fracture width as constant as possible would contribute more to fracture productivity which in turns contributes more to tight gas productivity. Moreover, the productivity of gas at different fracture half-lengths is also higher in the case of constant fracture height and constant fracture width compared to other three discussed cases.

\section{CONCLUSION}

The following conclusions can be drawn from this analysis:

(1) Increasing the fracture half-length by keeping constant fracture height and constant fracture width results in high amount of production. This is because of having large stimulated reservoir volume than any other cases.

(2) For constant height and changing width, the recovery obtained is higher for low fracture half-lengths, whereas for high fracture half-lengths changing height and constant width contributes more to the production. The value of constant height and changing width case, in high fracture half-lengths, can be higher if the width is high in more portion of fracture half-length.

(3) For better productivity in tight gas reservoirs and for an optimum fracture design, the fracturing parameters i.e. the fracture height and fracture width should be kept as constant as possible.

\section{ACKNOWLEDGEMENT}

We would like to acknowledge Petroleum Experts for their licensed Reveal Software. We are also grateful to Mehran University of Engineering and Technology, SZAB Campus, Khairpur Mirs' Sindh, Pakistan for allowing us to publish this paper.

\section{REFERENCES}

[1] Ostojic, J., Rezaee, R., \& Bahrami, H. (2012). Production performance of hydraulic fractures in tight gas sands, a numerical simulation approach. $J$. Pet. Sci. Eng. DOI:10.1016/j.petrol.2011.11.002.

[2] Zee Ma, Y., Moore, W. R., Gomez, E., Clark, W. J., \& Zhang, J. (2016). Chapter 14 - Tight Gas Sandstone Reservoirs, Part 1: Overview and Lithofacies. In: Zee Ma, Y., Holditch, S.A. (Eds.). Unconventional Oil and Gas Resources Handbook. Gulf Professional Publishing, Boston. pp. 405-427. DOI:10.1016/B978-0-12-802238-2.00014-6.

[3] Wang, R., Song, H., Tang, H., Wang, Y., Killough, J., \& Huang, G. (2016). Analytical modeling of gas production rate in tight channel sand formation and optimization of artificial fracture. Springer Plus. 5:540. DOI:10.1186/s40064-016-2176-7.

[4] Kalra, S., Tia, W. \& Wu, X. (2018). A numerical simulation study of $\mathrm{CO}_{2}$ injection for enhancing hydrocarbon recovery and sequestration in liquidrich shales. Pet. Sci. 15: 103-115. DOI:10.1007/s12182-017-0199-5.

[5] Medavarapu, K., Das, S., Ch, S., \& Nainwal, S. P. (2017). Optimization of fracturing technique for successful exploitation of tight gas reservoirs of Mandapeta field. In: SPE Oil and Gas India Conference and Exhibition, 4-6 April, Mumbai, India. DOI:10.2118/185421-MS.

[6] Taha, M., Khokhar, S. Y., Iqbal, M. S., Chughtai, S., Umair, M., \& Virk, M. A. (2013). Effective exploitation of tight gas reservoirs using Integrated Asset Modelling (IAM) approach. In: SPE/PAPG Annual Technical Conference, 26-27 November, Islamabad, Pakistan. DOI:10.2118/169646-MS

[7] Holditch, S. A. (2006). Tight gas sands. J. Pet. 58(06): 1-7. DOI:10.2118/103356-JPT.

[8] Peter, V., Lewis, N., Ali, A. D. (2010). Chapter 14 - Well stimulation. In: Economides, M. J., Watters, L. T., \& Dunn-Norman, S. (Eds.). Petroleum Well Construction. Wiley, pp. 656-717.

[9] Guo, B., Lyons, W. C., \& Ghalambor, A. (2007). Petroleum production engineering, A computer-assisted approach. (1st Ed.) Gulf Professional Publishing.

[10] Smith, M. B., and Shlyapobersky, J. W. (2000). Basics of hydraulic fracturing. In: Economides, M. J., \& Nolte, K. G. (Eds.). Reservoir stimulation ( $3^{\text {rd }}$ Edition). pp. 5-1 to 5-28.

[11] Zhang, L., Li, D., Wang, L., \& Lu D. (2015). Simulation of gas transport in tight/shale gas reservoirs by a multicomponent model based on PEBI grid. J. Chem. 2015:Art ID. 572434. DOI:10.1155/2015/572434. 
[12] Erturk, M. C., \& Sinayuc, C. (2015). Production performance analysis of unconventional gas reservoirs with different well trajectories and completion techniques. In: SPE Middle East Unconventional Resources Conference and Exhibition, 26-28 January, Muscat, Oman. DOI:10.2118/172944-MS.

[13] Mirzaei, M., \& Cipolla, C. L. (2012). A workflow for modeling and simulation of hydraulic fractures in unconventional gas reservoirs. In: SPE Middle East Unconventional Gas Conference and Exhibition, 23-25 January, Abu Dhabi, UAE. DOI:10.2118/153022-MS.

[14] Khan, W. A., Rehman, S. A., Akram, A. H., \& Ahmad, A. (2011). Factors affecting production behavior in tight gas reservoirs. In: SPE/DGS Saudi Arabia Section Technical Symposium and Exhibition, 15-18 May, Al-Khobar, Saudi Arabia. DOI:10.2118/149045-MS.

[15] Fazelipour, W. (2011). Development of techniques to integrate hydraulic fracturing design and reservoir simulation technologies - Application to forecast production of stimulated wells in unconventional gas reservoirs. In: SPE Middle East Unconventional Gas Conference and Exhibition, 31 January-2 February, Muscat, Oman. DOI:10.2118/142337-MS.

[16] Ionescu, F. G., Awemo, K. N., \& Pusch, G. (2006). Fracture design considerations for the development of tight gas formations. In: SPE
Europec/EAGE Annual Conference and Exhibition, 12-15 June, Vienna, Austria. DOI:10.2118/100231-MS.

[17] McGuire, W. J., \& Sikora, V. J. (1960). The effect of vertical fractures on well productivity. J. Pet. 12(10): 1-3. DOI:10.2118/1618-G.

[18] Cyrille, W. D. (2010). Production optimization of a tight sandstone gas reservoir with well completions: A numerical simulation study. Masters' Thesis. Texas Tech University.

[19] Ward, J. S., \& Morrow, N. R. (1987). Capillary pressures and gas relative permeabilities of low-permeability sandstone. SPE Formation Evaluation. 2(3): 345. DOI:10.2118/13882-PA.

[20] Khair, E. M. M. (2017). Effect of pump schedule on fracture geometry and shape during frac packing job. J. Pet. Environ. Biotechnol. 8: 342. DOI: $10.4172 / 2157-7463.1000342$.

[21] Chuprakov, D. A., \& Prioul, R. (2015). Hydraulic fracture height containment by weak horizontal interfaces. In: SPE Hydraulic Fracturing Technology Conference, 3-5 February, The Woodlands, Texas, USA. DOI:10.2118/173337-MS.

[22] Fisher, M. K., \& Warpinski, N. R. (2011). Hydraulic fracture-height growth: Real data. In: SPE Annual Technical Conference and Exhibition, 30 October-2 November, Denver, Colorado, USA. DOI:10.2118/145949MS. 